2018

\title{
Cripping the Ethics of Disability Arts Research
}

Roxanne Mykitiuk

Osgoode Hall Law School of York University, rmykitiuk@osgoode.yorku.ca

Andrea LaMarre

University of Guelph

Carla Rice

University of Guelph

\section{Source Publication:}

C. Macleod, J. Marx, P. Mnyaka \& G. Treharne (eds.). The Palgrave Handbook of Ethics in Critical Research. Switzerland: Palgrave MacMillan Press (2018) 257-272

Follow this and additional works at: https://digitalcommons.osgoode.yorku.ca/scholarly_works

Part of the Disability Studies Commons, and the Law Commons

\section{Repository Citation}

Mykitiuk, Roxanne; LaMarre, Andrea; and Rice, Carla, "Cripping the Ethics of Disability Arts Research" (2018). Articles \& Book Chapters. 2711.

https://digitalcommons.osgoode.yorku.ca/scholarly_works/2711

This Book Chapter is brought to you for free and open access by the Faculty Scholarship at Osgoode Digital Commons. It has been accepted for inclusion in Articles \& Book Chapters by an authorized administrator of Osgoode Digital Commons. 


\title{
CRIPPING THE ETHICS OF DISABILITY ARTS RESEARCH
}

\section{Chapter 13: Cripping the ethics of disability arts research}

\author{
in C. Macleod, J. Marx, P. Mnyaka \& G. Treharne (eds.). The Palgrave Handbook of Ethics in
}

Critical Research. Switzerland: Palgrave MacMillan Press (2018) 257-272.

Carla Rice Professor and Canada Research Chair, College of Social and Applied Human

Sciences, University of Guelph, Canada

Andrea LaMarre Doctoral Candidate, Department of Family Relations and Applied Nutrition, College of Social and Applied Human Sciences, University of Guelph, Canada

Roxanne Mykitiuk, Associate Professor of Law, Osgoode Hall, York University, Toronto, Canada

Abstract: The use of multimedia story making and drama based narrative in disability health research raises conventional ethical issues of informed consent, anonymity and confidentiality. In this chapter we explore unique ethical issues that arise when working with non-normatively embodied research participants in a highly collaborative way, using arts based mediums that transgress boundaries of anonymity and privacy, and call for difference-tailored processes of consent. People with disabilities have long been the object of medical and health research and the subjects of biomedical ethical transgressions, giving rise to the need for stricter human subject protocols about consent, confidentiality and anonymity. However, recent research collaborations with people with disabilities, where the participant's role as research subject and artist become blurred present an opportunity to investigate the specificity of embodied ethical issues. Embedded in institutional histories in which disabled bodies have been put on display or hidden away, ethical conundrums arise in the context of doing arts based research with people with disabilities where anonymity and confidentiality may not be desired by research participants and where contingent processes of consent (in which participants co-determine the timeframe, space, and audience for their art) may be greatly preferred. These are some of the ethical issues and practices arising out of our research with Re・Vision, a research centre for art and social justice, that uses the power of arts based methods to dismantle stereotypical understandings of disability and difference that create barriers to healthcare. Through Re•Vision's critical and participatory arts research processes, disability-identified and non-disabled researchers working to re-story disability and difference have come to be alive to the ethical conditions under which research participants/collaborators/artists wish to be identified and heard; with whom and under what conditions they are prepared to create and tell their stories; and how the curation of digital stories and narrative based drama gives rise to an ethics of voice and bearing witness. 
CRIPPING THE ETHICS OF DISABILITY ARTS RESEARCH

Word Count: 6097 


\section{CRIPPING THE ETHICS OF DISABILITY ARTS RESEARCH}

Negotiating artistic research within university strictures reveals a number of tensions: tensions around what we reveal and what we conceal, about who we are as researchers and human beings, and tensions related to offering anonymity and confidentiality while giving credit. As feminist academics committed to social justice, we struggle to negotiate these tensions in a way that prioritizes the needs and desires of participants. We also recognize that institutions require researchers to conduct our research in particular ways. Rules and regulations about ethical conduct developed out of a desire to protect both participants and researchers (Gray, Cooke \& Tannenbaum, 1978); in practice, however, they often leave us wondering about whose interests they end up serving — as well as how they shore up boundaries and firm lines between who is researcher and participant in research contexts.

In this chapter, we engage with tensions that arise between following university ethics protocols and co-producing research with participants - including artists with disabilities. We offer two case examples to illustrate complexities of voice, anonymity and confidentiality. In these examples, we explore: a) Times at which standard Research Ethics Board (REB) protocols regarding anonymity and confidentiality contravene participants' desires for recognition as artists; b) Processes of consent, including the possibility of conceptualizing consent as continuous and in flux; and c) Issues of voice, representation and aesthetics in the production of arts-based research. These case studies emerge from our work at Re•Vision, an art and social justice research centre at the University of Guelph in Canada, in which we conduct multimedia storytelling workshops and have co-created a research-based drama, Small Acts of Saying, with non-normatively embodied research participants. 


\section{CRIPPING THE ETHICS OF DISABILITY ARTS RESEARCH}

Our work is necessarily embedded in institutional histories in which disabled bodies have been put on display or hidden away (Rice, Chandler, Harrison, Liddiard, \& Ferrari, 2015); we found that in this context, disability-identified participants may not always desire anonymity and confidentiality, and may greatly prefer contingent and continuous processes of consent in which they co-determine the timeframe, space, and audience for their art. We do not offer definitive or universal solutions to ethical conundrums we have encountered-in fact, we hesitate to provide prescriptive instruction for fear of inscribing fixity on necessarily fluid processes. Instead, we discuss how to move beyond "tick box" approaches to working ethically with disability communities. Reaching beyond acknowledging people's rights to speak and act on their own behalf, we adopt a disability justice perspective, which we understand to mean being led by people with disabilities, pushing against ableist practices/ representations/ systems in our work processes/ outputs, and "cripping" or attending to and embracing the difference that disability makes to ethical decision-making in artistic research (Chandler cited in Reid, 2016, para 7). Cripping ethics, as we understand it, involves orienting to disabilities, not as differences that delimit or confound ethical processes, but as complex embodiments that, through challenging the normative standard of the human undergirding conventional ethical frameworks, expand possibilities for ethical conduct by opening the field of decision making in research. In this way, our discussion provides a jumping-off point for future exploration of the meaning and implementation of "cripping" ethical principles in and beyond academia.

\section{Re・Vision}

Re $\bullet$ Vision, an assemblage of arts-based research projects led by Dr. Carla Rice, innovated a Canadian Institutes for Health Research (CIHR)-funded initiative designed to speak back to dominant representations of disability using arts-based methods, including multimedia 


\section{CRIPPING THE ETHICS OF DISABILITY ARTS RESEARCH}

storytelling and research-based drama. Throughout the CIHR project, people with disabilities and healthcare providers (not mutually exclusive groups) created over 100 short, $2-5$ min films about their experiences. Participants made films at workshops in which we worked together to generate stories that centred the makers' voices. We adapted our workshop structure from StoryCenter's (formerly the Centre for Digital Storytelling) method of bringing people together to tell their stories using a digital format (Lambert, 2013). Additionally, Re•Vision incorporated facilitator trainings, wherein disability-identified individuals were trained in workshop facilitation; these facilitators then led subsequent workshops, including with healthcare providers as participants. By making their own self-reflexive films, researchers themselves became research participants and some also identified as members of Disability Arts communities beyond Re•Vision. As Re•Vision's work progressed, an emphasis on Disability Arts—and on incubating Disability Arts community_emerged (Chandler, Rice, Changfoot, LaMarre, Mykitiuk \& Mundel, forthcoming; Rice, Chandler, Liddiard, Rinaldi, \& Harrison, 2016). Filmmakers and facilitators often came from, went to, or created Disability Arts communities before, during, and/or after their engagement with Re•Vision. Project films have been screened in audiences ranging from healthcare providers to film festival attendees; at arts festivals and in community theatres; in classrooms and at conferences.

Thematically, the films challenge dominant medical models and representations of mind/body difference, including the troubling legacy of spectacalization of disabled bodies in reference textbooks and as cases for experimentation and medical fascination (GarlandThompson, 2007). They engage with storytellers' preferred perspectives on and representations of their lives. Healthcare provider stories similarly challenge dominant narratives, due in large 


\section{CRIPPING THE ETHICS OF DISABILITY ARTS RESEARCH}

part to disabled people's leadership, facilitation, and encouragement of providers to explore the role that mind/body difference plays in their own lives (Rice et al 2015).

Another component of Re•Vision's work was the development of a research-based drama, Small Acts of Saying. The play was an ensemble performance designed-similarly to the multimedia storytelling - to challenge taken-for-granted notions of disability that create healthcare barriers. Based in the devised theatre method (Milling \& Heddon, 2005), the play was developed collaboratively by a disability-identified director and disability/ difference identifying Re•Vision participant-performers. In this method, the devised theatre director "encourage[s], facilitate[s], edit[s] and guide[s] rather than impos[ing] his or her own interpretations" (Hayes, Cantillon \& Hafler, 2014). Performed for several audiences in the Fall of 2014, the play treated themes of embodied knowledge and re-imagined "accessibility" in the healthcare context.

\section{Arts-Based Research}

Broadly, arts-based research incorporates methods that extend beyond qualitative and quantitative approaches to learning about phenomena by integrating artistic expression. Artsbased methods are often conducted in a community-facing, participatory manner, where artists and participants either train in research processes or otherwise work in close proximity with researchers to enact research (Rice \& Mündel, under review). In our case, we also troubled the boundaries between researchers and researched, inviting researchers themselves to become implicated in the creation of art and engage in self-reflexive artistic practice. Participatory artsbased methods, like other community-based/ participatory research methods, have in common a commitment to re-envisioning "expertise" and challenging researchers to work with, rather than on or for participants (Israel et al. 2003). They do so by conceptualizing research processes as equally important as research outcomes; creativity and flexibility are valued in these methods 


\section{CRIPPING THE ETHICS OF DISABILITY ARTS RESEARCH}

(Boydell, Gladstone, Volpe, Allemang \& Stasiulis, 2012). Arts-based research carries the possibility for creating social change in and beyond the groups that conduct this research; the processes and products are commonly emotionally evocative, and act as creative explorations of what it means to live in the world and in a body in a particular way (Finley, 2014). Doing research in this way allows us to explore spaces in between how participants have been imagined by others and how they would prefer to imagine themselves (Rice, Chandler \& Changfoot, 2016).

Multimedia storytelling is one kind of arts-based research, a method that has been used in educational contexts as well as research spaces (LaMarre \& Rice, 2016; Rinaldi, Rice, LaMarre, Pendleton Jiménez, Harrison, Friedman, McPhail, Robinson, \& Tidgwell, 2016). It invites participants to tell their stories in a flexible multi-modal medium; participants give voice to their stories while simultaneously visually imagining them. The method opens up space for stories without words, stories that operate on multiple sensory registers, stories that leave us wondering. They invite participants to "speak from the flesh, to create and represent through the flesh and to construct and interpret their identities in mind and body" (Benmayor, 2008, p. 200). Of course, participants do not make stories in a space devoid of social meaning. Stories are made with a consciousness of audience and sense of time and place - while stories are intended to convey participants' embodied experiences as they are lived, stories are produced in a group context and often for a particular audience (Rice et al, 2016). Accordingly, just as these stories carry with them individual and social histories, so too do the spaces that surround their creation. Tensions of voice and purpose in storytelling have surfaced in our prior explorations of the impacts of the method on participants and audiences alike (e.g., Mykitiuk, Chaplick \& Rice, 2015).

Case Study One: Ethics of Confidentiality, Anonymity, and Acknowledgment 


\section{CRIPPING THE ETHICS OF DISABILITY ARTS RESEARCH}

Many, though not all, of the workshops conducted through Re•Vision included participants who self-identified as artists either before or after the workshops. Some workshop participants are self-identified artists and/or curators of disability arts; they bring works of art from where they are created to where they are viewed, moving from the (relatively) private sphere of artistic production to the public sphere of artistic viewing. Curation involves "bring[ing] different cultural spheres into contact" (Obrist, 2014, p. 24). In so doing, curators disrupt the gaze as it has been traditionally imposed upon people with disabilities — who have been made spectacles or examples in medical contexts and elsewhere (Rice, Chandler, Rinaldi, Liddiard, Changfoot, Mykitiuk, \& Mundel, forthcoming).

The importance of the curatorial tradition within the disability context cannot be overstated, both in terms of the ability to select and portray certain aspects of self and the choice of which aspects of bodily self to display (and to whom). A biomedical brush paints disability as abnormality; conditions requiring intervention and cure as aberrance caused by defective biology. In medical textbooks, people with disabilities have been used as examples of "rare" or "abnormal" conditions, sometimes as a "before" on the way to a "fixed" or "cured" body/mind or elsewise as examplar of the incurable, the tragic, the diseased (Garland-Thompson, 2012). Disabled bodies were (and still are) displayed in parts; faces covered with black boxes, identities concealed under the auspice of ethical conduct. This dehumanized representation of disabilitywhere people are reduced to the parts of their body/minds deemed defective-resembles the spectacalization of disability beyond the clinic or medical text - in historical "freak shows" and contemporary mass media alike (Sandell, Dodd \& Garland-Thompson, 2010). As Gay, with Fraser (2008) writes: 


\section{CRIPPING THE ETHICS OF DISABILITY ARTS RESEARCH}

Disabled people throughout the world are engaged with a long and complicated struggle with the way we are portrayed and the meanings attached to these portrayals that include disability as stigma, as a sign of a damaged soul, as being less than human, as dependent, weak, sexless, valueless. (p. 21)

Many participants in our storytelling workshops troubled the idea that to be included in the project they needed to adopt a pseudonym or have their identities concealed. This is not surprising, given the entwined legacies of being put on display or hidden away (in institutions and homes) with which disabled people have had to contend (Rice, 2014). Often, creators preferred to use their real names, and to own the artwork produced. Particularly when films were screened at film festivals or art shows, participating artists asserted their unquestionable right to be recognized for their work; and some took up leadership roles in curation in more than a conceptual sense.

Revealing storyteller identity is "a central aspect of making a political statement about a group," an especially salient task when those making the art are from misrepresented communities (Mykitiuk et al., 2015). Beyond the political, revealing storyteller identity is also an important part of reconfiguring roles in research encounters or at least of attenuating asymmetrical power relations between researcher and researched. As Scantlebury (2005) describes, researchers classically define boundaries between researcher and researched, as well as establish the overall direction and meaning of the project and goal of research relationships. Researchers working from feminist/critical perspectives commonly attend to power dynamics in research relationships, for instance working to facilitate participant comfort with data collection protocols and to underscore participant value (Blodgett et al. 2005). Researchers oriented toward community-based methods often work actively to share power, for instance inviting participants 


\section{CRIPPING THE ETHICS OF DISABILITY ARTS RESEARCH}

to join in deciding on the direction of the research, the questions asked, and sometimes data analysis (Banks et al., 2013). In Re•Vision, participants and researchers were not mutually exclusive categories - researchers became participants, and participants become researchers at various stages of the research processes. Still, we were conscious of the multiple roles we brought into the space, and of the ways in which power distribution remains unequal despite our 'cripping' of the roles of researcher and researched.

Arts-based research carries its own set of ethics considerations, including authorship, ownership, interpretation, and aesthetics, as well as more standard ethical considerations like informed consent, anonymity and confidentiality, and the emotionality that might emerge from the conduct of research (Boydell et al., 2012). The issue of artistic ownership and acknowledgment is particularly relevant to Re $\bullet$ Vision artist-participants, and has surfaced in and after our workshops. Lafrenière, Cox, Belliveau \& Lea (2013) question the ultimate ownership of artistic research: is a piece produced by an artist in the cadre of a research project an artistic product or a research output, or both? Who might be credited, and whose CV and career does the production enable? Boydell et al. (2012) offer a solution, wherein the artist owns creative research pieces once they have engaged with it; however, this is not an easy stance to adopt for all researchers, who argue for protecting research participants by minimizing artist "ownership" of "products." However, these examples apply to arts-based research projects where artists engage in knowledge translation/dissemination of previously conducted research, or where the artist is not themselves a participant in the research process. In our multimedia storytelling workshops and in the research-based drama, participants were themselves the artists- though the identity of artist itself carries particular complexities, and not all participants conceptualized themselves in that way. 


\section{CRIPPING THE ETHICS OF DISABILITY ARTS RESEARCH}

Playing an active role in framing their work was particularly important to those who identified as artist participants. We saw this commitment surface particularly when creators practiced as artists beyond the storytelling space. Filmmakers were eager to add the films to their CVs and to share their work in order to contribute to the growing Disability Arts movement in Canada (Chandler et al., forthcoming). A major part of being seen as more than a spectacle — as a human being with desires, preferences, and occupation, involves being more than a research participant. Given the problematic legacy of conducting research on people with disabilities, some artists agreed to participate in the research only because of its artistic components; many brought critical awareness of the ableism typically embedded in research practices and the need to 'crip' decision-making processes. It makes sense, then, that creators, as a condition of participation, would seek to control not only the content of the representations (and the conditions under which they were made) but also their screening and wider dissemination.

Despite our firm embrace of the disability justice principal that artist-participants' have the right to self-identify as artists/ creators, research ethics protocols frequently made this challenging. At the beginning of the project, this kind of research was novel for the Research Ethics Boards (REBs) with whom we were working and we went through many rounds of revisions with the REBs in finalizing our ethics protocols. In its first iteration, we were asked to do things that lay in tension with our commitments to enact truly cripped ways of doing research. For instance, we were asked to obscure the identities of all people in the multimedia stories, pixelating faces and changing voices to be unrecognizable. This REB was using standard ethical guidelines to justify the request - the need to maintain participant anonymity to protect against disclosures of participants' experiences to those who might be in a position to impact their lives 


\section{CRIPPING THE ETHICS OF DISABILITY ARTS RESEARCH}

in negative ways. Here, the expectation that anonymity would be preserved eerily echoed the legacy of reducing people with disabilities to "abnormal" or pathologized body/minds.

Another request that reproduced ableist logics, or re-inscribed the power of the nondisabled researcher and conflicted with disabled participants' control of their representations, was the expectation that researchers would a) not know or develop friendships with participants beyond the workshop space and b) would not re-contact participants after the project's end. These expectations foreclose the research relationship to the research encounter itself in a way that conflicts with a deeply-held disability justice-grounded commitment to a continual, processual and dynamic perspective on ethics that is based in relationships, reciprocity, trust, and care. Because of the problematic legacy of using the stories and bodies of people with disabilities to prop up the careers of researchers and more importantly still, uphold deeply ableist notions of normative humanity, there is a particular need to build reciprocity and trust in research relationships with disability communities. Likewise, the expectation of a particular brand of professionalism in the research space does not acknowledge how building reciprocal relationships and taking care create the conditions of possibility for telling stories that speak back. Being unable to re-contact participants afterwards both minimizes the possibility for building Disability Arts community and puts the power of decision-making around screening the stories and framing the art in the hands of researchers, rather than creators.

Terminating contact with participants further presumes that participants' stories are fixed and static, rather than fluctuating and changing with their subjectivities. It minimizes the possibility of envisioning consent as an ongoing dynamic process that may change as participants change. While informed consent has been a cornerstone of research ethics, the way that it is adopted in conventional research protocols envisions the process of obtaining consent as 


\section{CRIPPING THE ETHICS OF DISABILITY ARTS RESEARCH}

something that is done prior to research contact and closed after a signature has been obtained. When consent is described as a process, this generally extends only to the length of the study (Getz, 2002). In projects such as ours, where outputs may be screened or performed long after the research has "closed," we question the need to close out consent with study closure. After all, the stories participants tell at one moment may be far from their future realities. When this individual is a disability-identified artist practising on ableist terrain, they may assert the need for greater control over which versions of their selves they present through art into the future.

We learned the rubs between procedural and processual ethics through experimentation and failure. Even with our knowledge of the harms done to those with disabilities in research, of the spectacalization of the body/minds of abnormalized people and the commitment to cripping the process, we did not fully account for the inaccessibility of the ways in which research ethics can be inscribed onto research processes. We think it is important to acknowledge how our awareness of the limitations of procedural ethics came partly through our inability to anticipate all possible ethical conundrums that arise in this kind of research. Standard ethics procedures have their place, especially in preventing more overt or generally acknowledged violations of participants (such as in the now infamous Tuskegee Syphillis Experiment, where researchers withheld critical life-threatening/saving information from participants). These procedures were built to avoid repeating ethical misconduct, and are updated to reflect the ever-changing nature of ethical conduct. Acknowledging the dynamic, ever-changing nature of ethics would be a helpful step toward envisioning a more accommodating ethics process.

Every time participants alerted us to the discomfort they felt with participating in research as prescribed, we learned new ways of approaching the ethics process that would open to disability and enable a more radical processual ethics. For instance, through failing to account 


\section{CRIPPING THE ETHICS OF DISABILITY ARTS RESEARCH}

for the need to be able to re-contact participants before screening their work, we learned that we needed to state explicitly in our ethics protocols that we would be offering participants the opportunity to revisit their consent throughout the project and beyond. Through the REB request for pixilation, we discovered that we needed to introduce some critical theory into our research ethics requests, highlighting the history of the representation of disability as an assembly of abnormalized parts rather than a self-represented whole. We continue to grapple with tensions that emerge between participants preferred self-identification as artists and curators of their experiences, rather than research participants. This unresolved tension leads us to wonder, each time we distribute consent forms to participants, about the process of agreeing to participate in research and what that means for creators in terms of personal risk and perceived safety in research.

\section{Case Study Two: Voice and Staging in Small Acts of Saying}

Our research-based drama, Small Acts of Saying, equally brought up ethical tensions with which we continue to grapple. Mykitiuk et al. (2015) detail the reclaiming of staring in Small Acts of Saying, exploring audience reactions to arts-based research. In this paper, we reflect on curation in the process of decision-making around which stories to tell in the context of the play, noting again the performer awareness of audiences and possible readings of their performances. A review by Boydell et al. (2012) offers us a starting point for interrogating the ethical tensions of voice and representation, but largely presumes that the creator(s) of the artistic piece and the research participants are different people. In the case of the play, both dynamics operated—we had research participants who were performers, as well a disability-identified director who had directorial discretion in determining the overall aesthetic presentation of the play. Boydell et al. ask, "What if artists focus only on aspects that can be easily dramatized?" (p. 8). In Small Acts of 


\section{CRIPPING THE ETHICS OF DISABILITY ARTS RESEARCH}

Saying, we wondered not only about the selection of the stories to be told-necessarily a fraction of the sum total of participants' lives and embodied realities_-but about potential conflicts between the aesthetic and representational visions of the director and between various storytellers. Rooted as it is in the tradition of devised theatre, the play was grounded in the expectation that all people involved would have a role in determining its' devising and direction (Hayes et al., 2014). And yet, within the tradition of theatre, where the director's job is to lead, some voices are inevitably more dominant than others, and aesthetic decisions sometimes conflicted with political positions and research aims.

Here we see how accessibility requirements might conflict when negotiating voice/vision in the context of research-based drama - as well as the ways in which aesthetics, research purposes and researcher/performer politics come into tension. In the play, the director had conceptualized large boxes (signifying performers' medical files) as a major part of the deroulement of the dramatic action. Storytellers moved through space to engage with these boxes, dramatizing their stories in relation. Though the director envisioned the file box as an important part of the play's action, the devise paradoxically imposed normative ways of moving on some cast members, who struggled to carry their boxes. One cast member tripped and fell during a rehearsal. Despite this challenge to normative ways of moving, the director felt strongly about the presence of the boxes for the play's aesthetic integrity, and elected not to alter the aesthetic.

We do not present this tension as either a breach of ethics or as a power struggle, but as an illustration of how multiple visions and accessibility requirements simultaneously operate in disability arts research. Participants came into the space as people who had lived experience of being pathologized, controlled and monitored in many contexts as did the director, a disability 


\section{CRIPPING THE ETHICS OF DISABILITY ARTS RESEARCH}

artist who took up a position not previously open to those with embodied disability experience. Boydell (2011) comments on how performers may experience the emotional ramifications of engaging with challenging subject matter; in this case, however, rather than those without lived experience vicariously experiencing, performers with situated realities and lived experiences were re-exploring their own experiences and emotions. Reconciling various accessibility requirements is complicated by conflicting research, aesthetic, and political aims. At times, the commitment to present an aesthetically sophisticated piece contravened with the bodily realities of performers. These tensions also take shape through constraints imposed by the (neoliberalized) research apparatus itself, which necessitates the successful production of a polished art piece within the prescribed period, imposing pressures on performers to attend all rehearsals, to be on (normative) time, and to tell stories in a certain amount of time, etc. (Rice \& Mundel, under review). From a disability justice perspective, these constraints emerge as ethically problematic and surface the limits attempting to crip the arts through arts-based research.

For performers, telling stories is not necessarily enough to ensure that their voices are heard in the way that they want them to be heard. As with multimedia stories, the play is delivered to audiences that hold their own preconceived notions of performers' lived realitiesperceptions that necessarily impact their listening (Dion, 2009). The words are not delivered into an empty space of understanding, but filtered through ideas about what performers might be saying. As an example, one of the performers crafted a narrative designed to be humorous commentary; however, rather than reading the humour in the piece, audiences read the story as inspirational. This response was likely tethered to a preconceived understanding of people with disabilities as tragic victims or heroic survivors. Audiences, particularly medical audiences, are 


\section{CRIPPING THE ETHICS OF DISABILITY ARTS RESEARCH}

largely unused to hearing stories directly from people with disabilities that may actually have little to do with their pathologized "condition" — stories that may just be funny. Particularly in a play like Small Acts of Saying, where stories ranged from funny to angry to sad, audiences may not have been prepared to flip their reading beyond the conventionally told stories of disability.

Elsewhere, we have considered the "problematic of audiences," both in terms of how vulnerable stories might do harm to audiences and how audience responses may do harm to storytellers (Mykitiuk et al., 2015). Storytellers might fear that their stories will become "psychologized" or be misunderstood; this is particularly true with individuals whose stories have been repeatedly psychologized. A REB response to this concern might be to encourage anonymization of performers, or else have those without lived experience represent or dramatize the work. From a disability justice perspective, this re-inscribes ableist logics underpinning most disability representations (which position disabled people as research participants or allow for disability's humanization only when portrayed by non-disabled actors) rather than embracing crip logics that work to ensure people who embody difference are recognized as the performers, artists and researchers. Audiences may not be ready to hear stories as performers with disabilities wish them heard, however. The performer whose funny story was misread described how in the past they made what they now consider "bad art" in order to get people to listen; they told a story that would make audiences feel included. In Small Acts of Saying, they delivered a different kind of story — and that was mis-read. This leaves the disability-identified artist in the uncomfortable position of being, as they put it, "a pedagogical commodity for the telling of disability in a capitalist, artistic, $21^{\text {st }}$ Century," rather than an artist.

\section{Conclusion}




\section{CRIPPING THE ETHICS OF DISABILITY ARTS RESEARCH}

Research ethics protocols were built out of necessity, to help researchers avoid doing harm to those with less power in the research encounter. Without being open to difference, however, REBs lack, at times, the improvisational stance required when working differently with mind/body difference. Particularly in arts-based research, we have engaged in continual negotiations with REBs in order to do our work in a way that crips ethics. In enacting disability justice-oriented arts research, we have attempted to invite new ways of conceptualizing the researcher-participant relationship_ and the role of the "participant" itself_-into the research ethics world. We entered into this work with our own pre-conceived notions of what might be involved in conducting ethical disability arts research, based on our academic spaces of belonging as researchers and our social spaces of belonging as disability and non-disabilityidentified individuals who embrace social justice values. As we have moved in these spaces, we have inevitably failed. Through failure, we have reimagined how to do this work in a way that corresponds with a cripped ethic, welcoming in a plurality of experiences and ways of being.

Negotiating issues of voice, anonymity, and confidentiality is made complex by research “as usual”. Particularly when participants have a history of being slotted into boxes or dissembled into component parts, further imposing check-boxes, black boxes, and aesthetic boxes can have negative impacts on experiences of research. Through the cases of multimedia storytelling and research-based drama, we have offered critical examples of times at which participants challenged the standard ethics protocols given. In both cases, we grappled with issues of anonymity and confidentiality against a burgeoning Disability Arts community in Canada. Many participant-artists engaged with the project under the condition of being identified as artist. Pixelating faces, assigning pseudonyms, and showing multimedia stories in contexts of researchers' choosing contravene the expectation that artist-participants actively collaborate in 


\section{CRIPPING THE ETHICS OF DISABILITY ARTS RESEARCH}

the research from start to finish, and as such has the potential to re-colonize disabled people's stories as research products.

In the context of research-based drama, the development, staging and performance of Small Acts of Saying raised issues of voice and audience interpretation. It also alerted us to the impossibility, under ablest neoliberal logics, of simultaneously resolving conflicting accessibility requirements and conflicts between aesthetic, research, and political aims when ensemble casts, researchers, and directors work together to speak to audiences. All of this is held in tension against participant-performer desires for representation on their own terms in ways that acknowledge their unique artistic contributions to the ensemble. Here, we witness how rehearsed responses to ethical conundrums cannot acknowledge the complexity of disability and other arts

research. A "quick fix" to the potential for emotional harm on the part of the performer would be to have others perform their words, abstracting them from the audience and protecting their identities. However, doing so would require that we not acknowledge artists for their contributions.

Finally, arts-based research means creating a product—one that is more fixed and final than subjectivities and experiences. The stories participants tell are not representative of the entirety of their experiences, which are in flux and continually moving. In presuming that onetime consent can stand for the duration of the screening or performing of stories neglects to acknowledge the contextual, process-based nature of consent. Offering the opportunity to revisit consent and opening multiple options for levels of consent have acted as provisional ways of engaging with artist-participants to work toward a fuller acknowledgment of how circumstances and orientation to creative pieces can and do change and shift as time goes on. 


\section{CRIPPING THE ETHICS OF DISABILITY ARTS RESEARCH}

We consider a flexible and process-based orientation to ethical engagement with participants to be preferable to one that fixes ethics to a set of forms and procedures set out at the beginning and closed at the "end" of a research project. This has meant, for us, ongoing negotiations with both REBs and participant communities. It has meant a deeply contextualized consideration of ethics - including the ethical harms done to groups in the past in the name of "protection." We underscore the imperfection of this work, and the unfinished nature of the engagement with ethics itself. As we continue to conduct this research, we will inevitably stumble upon ways in which we could more closely attend to the ever-changing needs, conditions and understanding of participant communities. To close, we offer, rather than suggestions or directives for doing this kind of work, questions that we continue to ponder:

1. Do aesthetic, research, and political aims have to be in tension, or are there ways of aligning them?

2. Is it possible to mediate the telling of stories to avoid mis-reading without co-opting or claiming participants' stories as the researchers' or audiences' own?

3. What does it mean to 'crip' research ethics and how might a willingness to embrace disruption transform research processes and the knowledge produced? 


\section{CRIPPING THE ETHICS OF DISABILITY ARTS RESEARCH}

\section{References}

Banks, S., Armstrong, A., Carter, K., Graham, H., Hayward, P., Henry, A., Holland, T., Holmes, C., Lee, A., McNulty, A., Moore, N., Naylying, N., Stokoe, A. \& Strachan, A. (2013). Everyday ethics in community-based participatory research. Contemporary Social Science: Journal of the Academy of Social Science, 8(3), 263-277.

Benmayor, R. (2008). Digital storytelling as a signature pedagogy for the New Humanities. Arts \& Humanities in Higher Education, 7(2), 188-204.

Blodgett, L.J., Boyer, W. \& Turk, E. (2005). “No thank you, not today”: Supporting ethical and professional relationships in large qualitative studies. Forum Qualitative Sozialforschung / Forum Qualitative Social Research, 6(3), Art. 35.

Boydell, K.M. (2011a). Making sense of collective events: the co-creation of a research-based dance. Forum Qualitative Sozialforschung/Forum Qualitative Social Research, 12(1), Art. 5. Boydell, K.M., Gladstone, B.M., Volpe, T., Allemang, B. \& Stasiulis, E. (2012). The production and dissemination of knowledge: A scoping review of arts-based health research. Forum Qualitative Sozialforschung / Forum: Qualitative Social Research, 13(1), Art. 32, http://nbnresolving.de/urn:nbn:de:0114-fqs1201327

Boydell, K.M., Volpe, T., Cox, S., Katz, A., Dow, R., Brunger, F., Parsons, J., Belliveau, G., Gladstone, B., Zlotnik-Shaul, R., Cook, S., Kamensek, O., Lafrenière D., \& Wong, L. (2012). Ethical challenges in arts-based health research. International Journal of the Creative Arts in Interprofessional Practice, 11, http://www.ijcaip.com/archives/IJCAIP-11-paper1.html Chandler, E., Rice, C., Changfoot, N., LaMarre, A., Mykitiuk, R. \& Mundel, I. (under review) Cultivating disability arts in Ontario. 


\section{CRIPPING THE ETHICS OF DISABILITY ARTS RESEARCH}

Dion, S. D. (2009). Braiding histories: Learning from aboriginal peoples' experiences and perspectives. Vancouver British Columbia: UBC Press.

Finley, S. (2014). An introduction to critical arts-based research demonstrating methodologies and practices of a radical ethical aesthetic. Cultural Studies $\leftrightarrow$ Critical Methodologies, 14(6), 531- 532 .

Garland-Thomson, R. (2007). Shape structures story: fresh and feisty stories about disability. Narrative, 15(1), 113-23.

Garland-Thomson, R. (2012). The case for conserving disability. Journal of Bioethical Inquiry, 9(3), 339-355.

Gay, J. with Fraser, M. (2008). “Why does representation matter?” in J. Dodd, R. Sandell, D.

Jolly \& C. Jones (Eds.) Rethinking disability representations in museums and galleries.

Leicester: University of Leicester.

Getz, K.A. (2002). Informed consent process: A survey of subjects assesses strengths and weaknesses. Applied Clinical Trials, 11, 30-6.

Gray, B.H., Cooke, R.A. \& Tannenbaum, A.S. (1978). Research involving human subjects. Science, 201(4361), 1094-1101.

Hayes, P., Cantillon, P. \& Hafler, M. (2014). Discovering emotional honesty through devised theatre. The Clinical Teacher, 11(2), 84-87.

Israel, B.A., Schulz, A.J., Parker, E.A., Becker, A.B., Allen, A., Guzman, J.R. (2003). Critical issues in developing and following community-based participatory research principles. In M. Minkler \& N. Wallerstein (Eds.), Community-based participatory research for health (pp. 5673). San Francisco, CA: Jossey-Bass. 


\section{CRIPPING THE ETHICS OF DISABILITY ARTS RESEARCH}

LaMarre, A. \& Rice, C. (2016). Embodying critical and corporeal methodology: Digital storytelling with young women in eating disorder recovery. Forum: Qualitative Social Research / Sozialforschung, 17(2), Art. 7.

Lambert, J. (2013). Digital storytelling: Capturing lives, creating community. New York, NY: Routledge.

Lafrenière, D., Cox, S.M., Belliveau, G. \& Lea, G.W. (2013). Performing the human subject: Arts-based knowledge dissemination in health research. Journal of Applied Arts \& Health, 3(3), 243-257.

Milling, J. \& Heddon, D. (2005). Devising performance. New York: Palgrave Macmillan Mykitiuk, R., Chaplick, A., \& Rice, C. (2015). Beyond normative ethics: Ethics of arts-based disability research. Ethics, Medicine \& Public Health, 1, 373-382.

Obrist, H. U. (2014) Sharp Tongue, Loose Lips, Open Eyes, Ears to the Ground. Sternberg Press, London.

Reid J. (2015, May 5) Cripping the arts: It's about time. Canadian Art. https://canadianart.ca/features/cripping-arts-time/

Rice, C. Chandler, E. \& Changfoot, N. (2016). Imagining otherwise: The ephemeral spaces of envisioning new meanings. In C. Kelly \& M. Orsini (Eds.), Mobilizing metaphor: Art, culture and disability activism in Canada (pp. 54-75). Vancouver: UBC Press.

Rice, C., Chandler, E., Harrison, E., Liddiard, K. \& Ferrari, M. (2015). Project Re•Vision:

Disability at the edges of representation. Disability \& Society, 30(4), 513-527.

Rice, C., Chandler, E., Liddiard, K., Rinaldi, J., \& Harrison, E. (advanced online publication, 2016). The pedagogical possibilities for unruly bodies. Gender \& Education. DOI:

10.1080/09540253.2016.1247947. 


\section{CRIPPING THE ETHICS OF DISABILITY ARTS RESEARCH}

Rice, C., Chandler, E., Rinaldi, J., Liddiard, K., Changfoot, N., Mykitiuk, R. \& Mundel, I.

(forthcoming). Imagining disability futurities. Hypatia: A Journal of Feminist Philosophy.

Rice, C. \& Mundel, I. (under review). Multimedia storytelling methodology: Notes on access and inclusion in neoliberal times. Canadian Journal of Disability Studies.

Rice, C. (2014) Becoming women. Toronto: UT Press.

Rinaldi, J., Rice, C., LaMarre, A., Pendleton Jiménez, K., Harrison, E. Friedman, M., McPhail, D., Robinson, M. \& Tidgwell, T. (2016). “Through Thick and Thin”: Storying queer women’s experiences of taking up and resisting idealized body images and expected body management practices. Psychology of Sexualities Review (PoSR), 7 (2), 63-77.

Sandell, R., Dodd, J. \& Garland-Thompson, R. (2010). Re-presenting disability: Activism and agency in the museum. New York: Routledge.

Scantlebury, K. (2005). Maintaining ethical and professional relationships in large qualitative studies: A Quixotic ideal? Forum: Qualitative Social Research / Sozialforschung, 6(3), Art. 39. 